\title{
CHEMICAL INTENSIFICATION OF NONLINEAR MULTI-WAVE INTERACTIONS
}

\author{
M. G. GALUSHKIN, E. B. GORDON, M. S. DROZDOV \\ and K. A. SVIRIDOV \\ Institute for Energy Problems of Chemical Physics, Academy of Sciences, \\ 142432 Chernogolovka, Moscow, Russia
}

Nonlinear interaction of laser emission with a chemically reactive medium, in which a branched chain reaction may readily occur, has been analyzed aiming at essential intensification the contrast of photochemically induced phase gratings. For the model system $\mathrm{CS}_{2} / \mathrm{O}_{2}$, the degenerated four-wave mixing is theoretically studied under the assumption of $\mathrm{CS}_{2}$ photodissociation followed by subsequent secondary reactions induced by reactive photodissociation products. For varied $\mathrm{CS}_{2}$ concentrations and incident flux intensities, the dynamics of nonlinear reflection has been analyzed and same laser applications of such systems are suggested.

KEY WORDS: Degenerated four-wave mixing, photodissociation, carbon disulfide

Nonlinear interaction of laser emission with chemically reactive media has been widely discussed previously. ${ }^{1-6}$ Considerable attention was paid to the phenomena of stimulated scattering ${ }^{3,5}$ and degenerated four-wave mixing (DFWM) ${ }^{4,6}$ For the case of short-wavelength emission (e.g., of excimer lasers), photochemical transformations induced by this emission (in particular, photodissociation) seem to be of great significance for the problem under consideration. It may also be expected that the contrast of primarily formed phase gratings would be intensified in subsequent chemical reactions induced by photodissociation products. From this point of view, photoinduced chain and branched chain reactions may turn out to be very promising.

In the first suggestion ${ }^{7}$ on utilization of photodissociation in nonlinear optics, only the alterations in polarizability of starting molecules and dissociation products were taken into account. However, as a matter of fact, primary photochemical action

$$
\mathrm{RA}+\mathrm{h} v \rightarrow \mathrm{R}+\mathrm{A}
$$

may result in a number of alterations in the system which may eventually lead to nonlinear interactions :

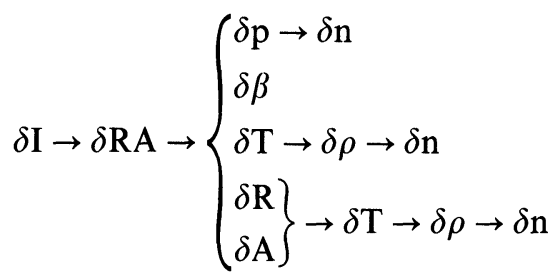


where $\delta \mathrm{x}$ are variations of : laser emission intensity $\mathrm{I}$; concentrations of starting molecules RA and decomposition products $\mathrm{R}$ and $\mathrm{A}$; polarizability of medium $\mathrm{p}$; absorption $\beta$; temperature $\mathrm{T}$; density $\rho$; and refractive index $\mathrm{n}$, respectively. The next types of non-linearity may be outlined: polarizational (1), concentrationamplitude (2), direct thermal (3) and chemically induced thermal (4) ones. The latter one causes by heat release in chemical reactions of photodissociation products was analyzed previously ${ }^{5}$ as applied to the case of stimulated scattering. It should be noted that the several of the mentioned mechanisms of nonlinearity may provide a contribution into self-influence processes. In the present communication, we report on the data of theoretical study of DFWM upon photodissociation arising due to all the four types of nonlinearity (1-4).

The nonlinear equation for electromagnetic field may be written as follows:

$$
\nabla^{2} \mathrm{E}+\mathrm{k}^{2}\left(1+\frac{2 \delta \mathrm{n}}{\mathrm{n}_{0}}\right) \mathrm{E}-\mathrm{ik}(\beta+\delta \beta) \mathrm{E}=0
$$

where $\mathrm{E}=\mathrm{E}_{1}+\mathrm{E}_{2}+\mathrm{E}_{3}+\mathrm{E}_{4}, \mathrm{E}_{1}=\left[\frac{1}{2} \mathrm{~A}_{1} \exp \left(-\mathrm{i} \overline{\mathrm{k}}_{1} \overline{\mathrm{r}}\right)+\right.$ complex conjugate value $]$ and $E_{2}=\left[\frac{1}{2} A_{2} \exp \left(-\mathrm{ik}_{2} \overline{\mathrm{r}}\right)+\right.$ complex conjugate value $]$ are the pump waves $\left(\bar{k}_{2}=-\bar{k}_{1}\right) ; E_{3}=\left[\frac{1}{2} a_{3} \exp (-i k z)+\right.$ complex conjugate value $]$ stands for signal wave; $\mathrm{E}_{4}=\left[\frac{1}{2} \mathrm{a}_{4} \exp (\mathrm{ikz})+\right.$ complex conjugate value $)$ is phase conjugated return wave; and $k=2 \pi / \lambda$ is wave number. Spatial gratings, initiated by optical waves and intensificated by chemical reactions, dissipate as the result of diffusion and thermal conductivity. For this reason equation (5) must be solved together with material equations of chemical kinetics, diffusion and thermal conductivity.

As an example, in the further discussion we shall consider photodissociation of carbon disulphide in the presence of oxygen and buffer gas Xe induced by emission $\lambda 193.3 \mathrm{~nm}$ (emission from excimer ArF laser). Under appropriate conditions, the branched chain oxidation of $\mathrm{CS}_{2}$ may take place, according to the scheme ${ }^{8}$ :

$$
\begin{gathered}
\mathrm{CS}_{2}+\mathrm{h} v \rightarrow \mathrm{CS}+\mathrm{S}+\mathrm{Q}_{1} \\
\mathrm{~S}+\mathrm{O}_{2} \stackrel{\mathrm{k}_{2}^{\prime}}{\rightarrow} \mathrm{SO}+\mathrm{O}+\mathrm{Q}_{2} \\
\mathrm{O}+\mathrm{CS}_{2} \stackrel{\mathrm{k}_{2}^{\prime}}{\rightarrow} \mathrm{CS}+\mathrm{SO}+\mathrm{Q}_{3} \\
\mathrm{O}+\mathrm{CS}_{4}^{\mathrm{k}_{4}^{\prime}} \mathrm{CO}+\mathrm{S}+\mathrm{Q}_{4} \\
\mathrm{SO}+\mathrm{O}_{2} \stackrel{\mathrm{k}_{5}^{\prime}}{\rightarrow} \mathrm{SO}_{2}+\mathrm{O}+\mathrm{Q}_{5} \\
\mathrm{CS}+\mathrm{O}_{2} \stackrel{\mathrm{k}_{6}^{\prime}}{\rightarrow} \mathrm{OCS}+\mathrm{O}+\mathrm{Q}_{6}
\end{gathered}
$$

Note that chemical branching takes place in the two latter reactions.

The equations of homogeneous chemical kinetics may be written in form:

$$
\frac{\mathrm{d}}{\mathrm{dt}}\left[\mathrm{CS}_{2}\right]=-\Psi_{1}-\Psi_{3}, \quad \frac{\mathrm{d}}{\mathrm{dt}}[\mathrm{CS}]=\Psi_{1}+\Psi_{3}-\Psi_{4}-\Psi_{6}
$$




$$
\begin{gathered}
\frac{\mathrm{d}}{\mathrm{dt}}[\mathrm{S}]=\Psi_{1}-\Psi_{2}+\Psi_{4}, \quad-\frac{\mathrm{d}}{\mathrm{dt}}\left[\mathrm{O}_{2}\right]=\Psi_{2}+\Psi_{5}+\Psi_{6} \\
\frac{\mathrm{d}}{\mathrm{dt}}[\mathrm{O}]=\Psi_{2}-\Psi_{3}-\Psi_{4}+\Psi_{5}+\Psi_{6}, \quad \frac{\mathrm{d}}{\mathrm{dt}}[\mathrm{CO}]=\Psi_{4}, \quad \frac{\mathrm{d}}{\mathrm{dt}}\left[\mathrm{SO}_{2}\right]=\Psi_{5} \\
\frac{\mathrm{d}}{\mathrm{dt}}[\mathrm{OCS}]=\Psi_{6}, \quad \frac{\mathrm{d}}{\mathrm{dt}}[\mathrm{SO}]=\Psi_{2}+\Psi_{3}-\Psi_{5}
\end{gathered}
$$

where $\Psi_{1}=\sigma \mathrm{I}\left[\mathrm{CS}_{2}\right], \Psi_{2}=\mathrm{k}_{2}^{\prime}\left[\mathrm{O}_{2}\right][\mathrm{S}], \Psi_{3}=\mathrm{k}_{3}^{\prime}[\mathrm{O}]\left[\mathrm{CS}_{2}\right], \Psi_{4}=\mathrm{k}_{4}^{\prime}[\mathrm{O}][\mathrm{CS}]$, $\Psi_{5}=\mathrm{k}_{5}^{\prime}\left[\mathrm{O}_{2}\right][\mathrm{SO}], \Psi_{6}=\mathrm{k}_{6}^{\prime}\left[\mathrm{O}_{2}\right][\mathrm{CS}], \sigma \simeq 1 \times 10^{17} \mathrm{~cm}^{2},{ }^{9} \mathrm{k}_{2}^{\prime}=2.2 \times 10^{-12} \mathrm{~cm}^{3} / \mathrm{s}$, $\mathrm{k}_{3}^{\prime}=5 \times 10^{-12} \mathrm{~cm}^{3} / \mathrm{s}, \mathrm{k}_{4}^{\prime}=2.9 \times 10^{-11} \mathrm{~cm}^{3} / \mathrm{s}, \mathrm{k}_{5}^{\prime}=5.8 \times 10^{-13} \exp (-6500 / \mathrm{RT})$ $\mathrm{cm}^{3} / \mathrm{s}, \mathrm{k}_{6}^{\prime}=1.7 \times 10^{-11} \exp (-15000 / \mathrm{RT}) \mathrm{cm}^{3} / \mathrm{s}, \mathrm{Q}_{1}=\mathrm{h} v-\mathrm{D}_{\text {Dis }}=42.4 \mathrm{Cal} / \mathrm{mol}$, $\mathrm{Q}_{2}=6 \mathrm{Cal} / \mathrm{mol}, \mathrm{Q}_{3}=22 \mathrm{Cal} / \mathrm{mol}, \mathrm{Q}_{4}=85 \mathrm{Cal} / \mathrm{mol}, \mathrm{Q}_{5}=11 \mathrm{Cal} / \mathrm{mol}, \mathrm{Q}_{6}=$ $37 \mathrm{Cal} / \mathrm{mol}^{8}$

For specific rate of heat release, we have

$$
\mathrm{Q}=\sum_{\mathrm{i}=1}^{6} \mathrm{Q}_{\mathrm{i}} \Psi_{\mathrm{i}}
$$

where $Q_{i}$ is thermal effect of the $i$-th reaction, including photodissociation. Heat release results in temperature increase and subsequent density alterations. Upon pressure levelling off, the equation of heat conduction

$$
\rho \mathrm{C} \frac{\partial \mathrm{T}}{\partial \mathrm{t}}-\rho \mathrm{C} \chi \nabla^{2} \mathrm{~T}=\mathrm{Q}
$$

holds true, where $\mathrm{C}$ is specific heat capacity of medium and $\chi$ is thermometric conductivity.

In DFWM, the intensity of photon is represented as $\mathrm{I}=\mathrm{I}_{0}+\delta \mathrm{I}$, where $\delta \mathrm{I} \ll \mathrm{I}_{0}$; the value of $\delta \mathrm{I}$ is given by

$$
\begin{aligned}
\delta \mathrm{I}= & \frac{\mu}{2}\left[\mathrm{~A}_{1} \exp \left(-\mathrm{i} \overline{\mathrm{k}}_{1} \overline{\mathrm{r}}\right)+\mathrm{A}_{2} \exp \left(-\mathrm{i \overline {k } _ { 2 }} \overline{\mathrm{r}}\right)\right] \times\left[\mathrm{a}_{3}^{*} \exp (\mathrm{ikz})+\mathrm{a}_{4}^{*} \exp (-\mathrm{ikz})\right] \\
& + \text { complex conjugate value }
\end{aligned}
$$

Variation $\delta \mathrm{I}$ corresponds to variations of concentrations of all the components of mixture $\left(\mathrm{R}_{\mathrm{i}}=\mathrm{CS}_{2}, \mathrm{O}_{2}, \mathrm{CS}, \mathrm{S}, \mathrm{SO}, \mathrm{O}, \mathrm{CO}, \mathrm{SO}_{2}, \mathrm{OCS}\right)$, as well as of heat release $\delta \mathrm{Q}$, temperature $\delta \mathrm{T}$ and density $\delta \rho=-(\delta \mathrm{T} / \mathrm{T}) \rho$. As a result, for variation of absorption coefficient we obtain

$$
\delta \beta=\sigma \delta\left[\mathrm{CS}_{2}\right],
$$

for phase thermal nonlinearity

$$
\delta \mathrm{n}=\mathrm{K}_{\mathrm{G}} \delta \rho,
$$


for polarizational nonlinearity

$$
\delta \mathrm{n}=\sum_{\mathrm{i}=1}^{9}\left(\mathrm{n}_{\mathrm{i}}^{0}-1\right) \frac{\delta\left[\mathrm{R}_{\mathrm{i}}\right]}{\mathrm{N}_{\mathrm{L}}}
$$

where $N_{L}$ is Loschmidt's number, $n_{i}^{0}$ is refractive index for the $i$-th component at normal conditions, $\mathrm{K}_{\mathrm{G}}$ is the Gladstone-Dale constant.

The equations for variations of concentrations of all the components follow from the equations of chemical kinetics (7), whereas for $\delta \mathrm{T}$ from Eq. (9), diffusion of species being taken into account. ${ }^{4}$ Separating high-frequency spatial oscillations of variations of all the functions under consideration, we may obtain the equations for slowly changing spatial amplitudes of interacting waves and the parameters of medium ${ }^{4}$ :

$$
\begin{aligned}
& \frac{\partial \mathrm{A}_{1}}{\partial \mathrm{z}}=\frac{-1}{2} \beta \mathrm{A}_{1}-\frac{\sigma \mu}{4}\left[\left(\delta\left[\mathrm{CS}_{2}\right]_{1}+\delta\left[\mathrm{CS}_{2}\right]_{4}\right)\left|\mathrm{a}_{3}\right|+\left(\delta\left[\mathrm{CS}_{2}\right]_{2}+\delta\left[\mathrm{CS}_{2}\right]_{3}\right)\left|\mathrm{a}_{4}\right|\right] \times \mathrm{e}^{\mathrm{i} \varphi_{1}} \\
&+\mathrm{i} \frac{\mathrm{k} \mu}{\mathrm{n}_{0}}\left[\left(\mathrm{~b}_{1}+\mathrm{b}_{2}\right)\left|\mathrm{a}_{3}\right|+\left(\mathrm{b}_{2}+\mathrm{b}_{3}\right)\left|\mathrm{a}_{4}\right|\right] \times \mathrm{e}^{\mathrm{i} \varphi_{1}} \\
&-\frac{\partial \mathrm{A}_{2}}{\partial \mathrm{z}=}-\frac{1}{2} \beta \mathrm{A}_{2}-\frac{\sigma \mu}{4}\left[\left(\delta\left[\mathrm{CS}_{2}\right]_{3}+\delta\left[\mathrm{CS}_{2}\right]_{2}\right)\left|\mathrm{a}_{3}\right|\right. \\
&\left.+\left(\delta\left[\mathrm{CS}_{2}\right]_{1}+\delta\left[\mathrm{CS}_{2}\right]_{4}\right)\left|\mathrm{a}_{4}\right|\right] \times \mathrm{e} \times \mathrm{i} \varphi_{2} \\
&+\mathrm{i} \frac{\mathrm{k} \mu}{\mathrm{n}_{0}}\left[\left(\mathrm{~b}_{2}+\mathrm{b}_{3}\right)\left|\mathrm{a}_{3}\right|+\left(\mathrm{b}_{1}+\mathrm{b}_{4}\right)\left|\mathrm{a}_{4}\right|\right] \times \mathrm{e}^{\mathrm{i} \varphi_{2}} \\
& \frac{\partial \overline{\overline{\mathrm{A}}_{3}}}{\partial \mathrm{z}}=-\frac{1}{2} \beta \overline{\overline{\mathrm{A}}}_{3}-\frac{\sigma \mu}{4}\left[\left(\delta\left[\mathrm{CS}_{2}\right]_{1}+\delta\left[\mathrm{CS}_{2}\right]_{4}\right)\left|\mathrm{A}_{1}\right|\right. \\
&\left.+\left(\delta\left[\mathrm{CS}_{2}\right]_{2}+\delta\left[\mathrm{CS}_{2}\right]_{3}\right)\left|\mathrm{A}_{2}\right|\right] \times \mathrm{e}^{\mathrm{i} \varphi_{3}} \\
&+\mathrm{i} \frac{\mathrm{k} \mu}{\mathrm{n}_{0}}\left[\left(\mathrm{~b}_{1}+\mathrm{b}_{4}\right)\left|\mathrm{A}_{1}\right|+\left(\mathrm{b}_{2}+\mathrm{b}_{3}\right)\left|\mathrm{A}_{2}\right|\right] \times \mathrm{e}^{\mathrm{i} \varphi_{3}} \\
&-\frac{\partial \mathrm{a}_{4}}{\partial \mathrm{z}}=-\frac{1}{2} \beta \mathrm{a}_{4}-\frac{\sigma \mu}{4}\left[\left(\delta\left[\mathrm{CS}_{2}\right]_{2}+\delta\left[\mathrm{CS}_{2}\right]_{3}\right)\left|\mathrm{A}_{1}\right|\right. \\
&\left.+\left(\delta\left[\mathrm{CS}_{2}\right]_{2}+\delta\left[\mathrm{CS}_{2}\right]_{4}\right)\left|\mathrm{A}_{2}\right|\right] \times \mathrm{e}^{\mathrm{i} \varphi_{4}} \\
&+\mathrm{i} \frac{\mathrm{k} \mu}{\mathrm{n}_{0}}\left[\left(\mathrm{~b}_{1}+\mathrm{b}_{4}\right)\left|\mathrm{A}_{2}\right|+\left(\mathrm{b}_{2}+\mathrm{b}_{3}\right)\left|\mathrm{A}_{1}\right|\right] \times \mathrm{e}^{\mathrm{i} \varphi_{4}} \\
& \rho \mathrm{C} \frac{\partial \delta \mathrm{T}_{\mathrm{j}}}{\partial \mathrm{t}}+ \rho \mathrm{C} \chi \mathrm{q}_{\mathrm{j}}^{2} \delta \mathrm{T}_{\mathrm{j}}=\delta \mathrm{Q}_{\mathrm{j}}-\frac{\mathrm{Q}}{\rho} \delta \rho_{\mathrm{j}}, \quad \delta \rho_{\mathrm{j}}=-\frac{\delta \mathrm{T}_{\mathrm{j}}}{\mathrm{T}} \rho
\end{aligned}
$$

Here $\mathrm{b}_{\mathrm{j}}=\mathrm{K}_{\mathrm{G}} \delta \rho_{\mathrm{j}}+\sum_{\mathrm{i}=1}^{9}\left(\mathrm{n}_{\mathrm{i}}^{0}-1\right) \frac{\delta\left[\mathrm{R}_{\mathrm{i}}\right]}{\mathrm{N}_{\mathrm{L}}}, \mathrm{j}=1,2,3,4, \quad \mu=\mathrm{c} / 8 \pi$; 
$\mathrm{q}_{1}=\mathrm{q}_{4}=2 \mathrm{k} \sin \left(\theta_{1} / 2\right), \mathrm{q}_{2}=\mathrm{q}_{3}=2 \mathrm{k} \sin \left(\theta_{2} / 2\right), \theta_{1}+\theta_{2}=\pi, \theta_{1}$ is the angle between the wave vectors of the signal wave and one of the pump waves.

In the preset signal wave intensity approximation ${ }^{4}$ from Eq. (17) with boundary condition $a_{4}(L)=0$, where $L$ is the range of interaction, we obtain

$$
\begin{aligned}
\mathrm{a}_{4}(\mathrm{z})= & -\left[\frac{\sigma \mu}{4}\left(\delta\left[\mathrm{CS}_{2}\right]_{1}\left|\mathrm{~A}_{2}\right|+\delta\left[\mathrm{CS}_{2}\right]_{3}\left|\mathrm{~A}_{1}\right|\right)\right. \\
& \left.+\mathrm{i} \frac{\mathrm{k} \mu}{2 \mathrm{n}_{0}}\left(\mathrm{~b}_{1}\left|\mathrm{~A}_{2}\right|+\mathrm{b}_{3}\left|\mathrm{~A}_{1}\right|\right)\right] \times \frac{1}{\beta} \mathrm{e}^{-\mathrm{i} \varphi_{3}} \cdot\left[1-\mathrm{e}^{-0.5 \beta(\mathrm{L}-\mathrm{z})}\right]
\end{aligned}
$$

Reflectivity referred to square of length $(R<1)$ is then given by:

$$
\begin{aligned}
\frac{\mathrm{R}}{\mathrm{L}^{2}}=\left|\frac{\mathrm{a}_{4}(0)}{\mathrm{a}_{3}(0)}\right|^{2}= & {\left[\left(\frac{\sigma \mu}{4}\right)^{2}\left(\delta\left[\mathrm{CS}_{2}\right]_{1}\left|\mathrm{~A}_{2}\right|+\delta\left[\mathrm{CS}_{2}\right]_{3}\left|\mathrm{~A}_{1}\right|\right)^{2}\right.} \\
& \left.+\frac{\mathrm{k}^{2} \mu^{2}}{4 \mathrm{n}_{0}^{2}}\left(\mathrm{~b}_{1}\left|\mathrm{~A}_{2}\right|+\mathrm{b}_{3}\left|\mathrm{~A}_{1}\right|\right)^{2}\right] \times\left[1-\mathrm{e}^{-0.5 \beta \mathrm{L}}\right]^{2} / \beta^{2} \mathrm{~L}^{2}
\end{aligned}
$$

The first term in square brackets in (20) corresponds to reflection at amplitude gratings, while the second term to reflection at phase gratings.

To elucidate the particular features of concentration-amplitude nonlinearity in DFWM, let us assume that intensities of pump waves are independent of time and that $I_{1}=I_{2}=I_{H}$. These simplifications are not of essential importance and are used only for the sake of simplicity. Then by using the first of equations (18) in combination with (19), we obtain:

$$
\begin{aligned}
& \delta\left[\mathrm{CS}_{2}\right]_{1}\left|\mathrm{~A}_{2}\right| \sim \sigma\left[\mathrm{CS}_{2}\right]_{0} \times \mathrm{I}_{\mathrm{H}} \times \mathrm{t} \times \exp \left(-2 \sigma \mathrm{I}_{\mathrm{H}} \mathrm{t}\right) \\
& \delta\left[\mathrm{CS}_{2}\right]_{3}\left|\mathrm{~A}_{1}\right| \sim \sigma\left[\mathrm{CS}_{2}\right]_{0} \times \mathrm{I}_{\mathrm{H}} \times \mathrm{t} \times \exp \left(-2 \sigma \mathrm{I}_{\mathrm{H}} \mathrm{t}\right)
\end{aligned}
$$

Reflection factor $\mathrm{R} / \mathrm{L}^{2}$ is easily seen to attain its maximal value at $\mathrm{t}=\left(2 * \sigma * \mathrm{I}_{\mathrm{H}}\right)^{-1}$, its maximal value being independent of the intensity of pump waves and determined only by the initial concentration of photodissociating component and absolute absorption cross-section:

$$
\mathrm{R} / \mathrm{L}^{2}=\left(\sigma\left[\mathrm{CS}_{2}\right]_{0} / 4 \mathrm{e}\right)^{2}
$$

The result obtained has a clear physical meaning: maximal contrast of grafting is attained when nearly half of initial $\mathrm{CS}_{2}$ is subjected to photodecomposition (of course, under conditions when $\mathrm{t}_{1} \ll \tau_{\text {chem }}$, where $\tau_{\text {chem }}$ is characteristic time of chain chemical reaction), whereas maximal reflection factor is determined by the reciprocal absorption pathlength $\left(\sigma\left[\mathrm{CS}_{2}\right]_{0}\right)$.

If the absorption cross-section $\sigma$ is sufficiently large (as is for the case of $\mathrm{CS}_{2}$ ), the abovementioned situation, when the concentration-amplitude nonlinearity is prevailing over the direct-thermal and polarizational nonlinearities, will be realized at relatively low intensities of laser emission $I_{1} \geqslant(2 \sigma \tau)^{-1}$. The reason for such a behavior is almost entire photodecomposition of absorbing species within the time interval $\tau$ of laser pulse. The photodissociation-induced gratings proved to have a 
contrast sufficient to perform the optical phase conjugation of the ns laser pulses of such low energy as $0.1 \mathrm{~J} / \mathrm{cm}^{2}$.

The numerical simulation of the equations mentioned above was performed by using the standard Kutta-Merson procedure.

Figures 1 and 2 present reflection factor as function of time for varied intensities of reference waves and initial $\mathrm{CS}_{2}$ concentrations. These data are in line with the abovementioned qualitative considerations and illustrate high efficiency of the concentration-amplitude mechanism of nonlinearity arising upon $\mathrm{CS}_{2}$ photodissociation by the emission from an excimer laser.

It seems natural that the nonlinearities associated with heat release in photoinduced branched chain reactions should be expected to occur at the time scales characteristic of the induction periods for these reactions, i.e. at large time delay.

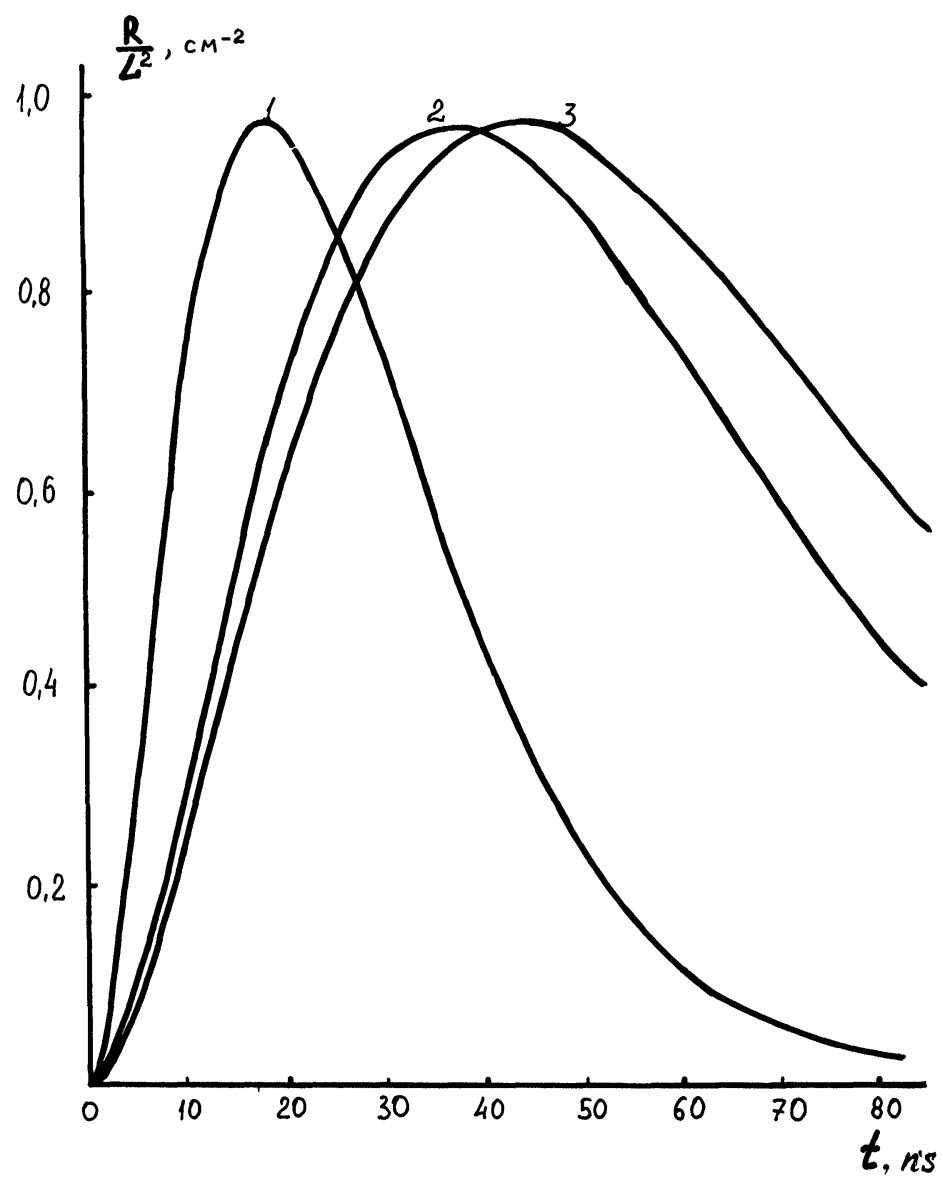

Figure 1 Dynamics of reflection from amplitude gratings upon photolysis of the $\mathrm{CS}_{2}+3 \mathrm{O}_{2}$ mixture $\left(\left[\mathrm{CS}_{2}\right]=2.68 \times 10^{17} \mathrm{~cm}^{-3}, \mathrm{~T}=300 \mathrm{~K}\right)$ for varied intensities of pumping beam $\mathrm{I}_{\mathrm{H}}=2 \times 10^{5} \mathrm{~N}_{\mathrm{L}}$ photon $/ \mathrm{cm}^{2} \cdot \mathrm{s}(1) ; 1 \times 10^{5} \mathrm{~N}_{\mathrm{L}}(2) ; 8.5 \times 10^{4} \mathrm{~N}_{\mathrm{L}}(3)$; where $\mathrm{N}_{\mathrm{L}}=2.68 \times 10^{19}$ is the Loschmidt number. 


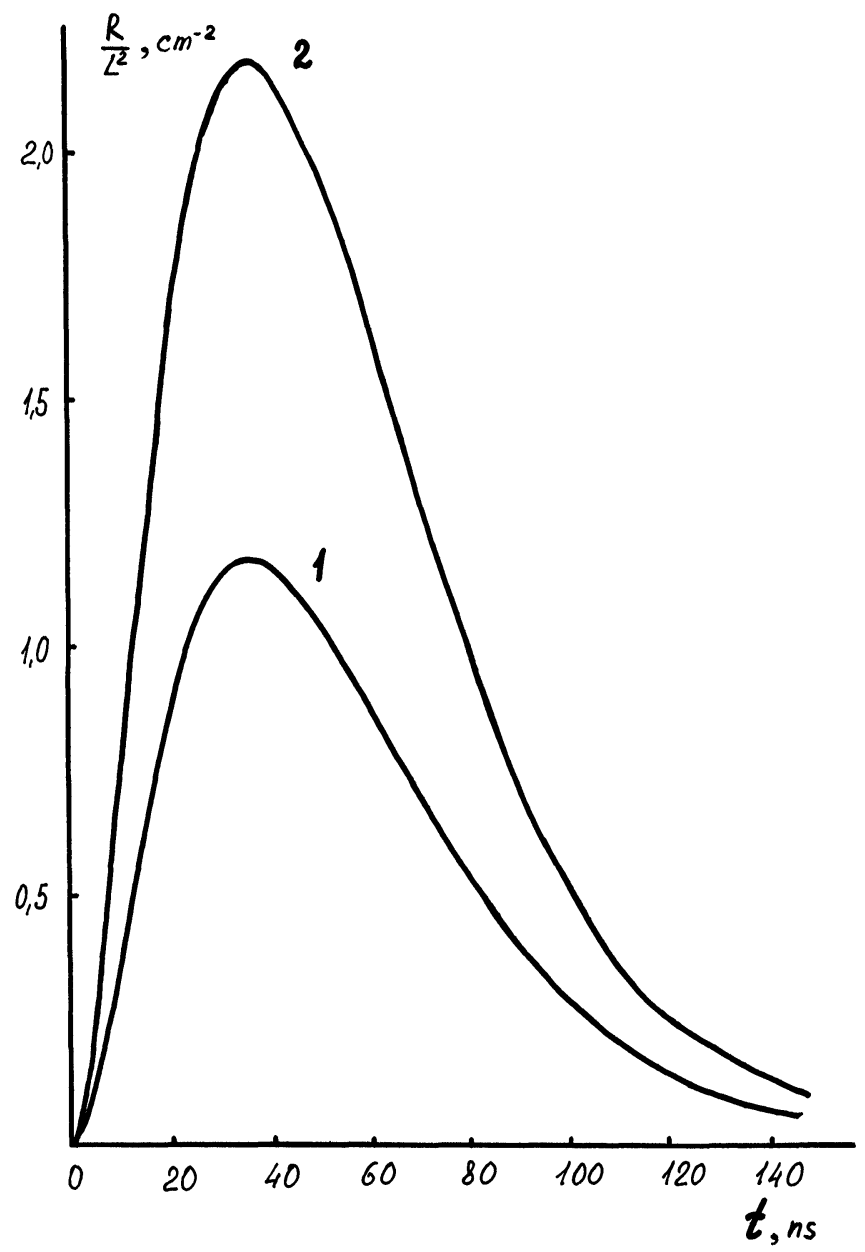

Figure 2 The time dependence of reflection factor $R / L^{2}$ from amplitude gratings for two different concentrations $\left[\mathrm{CS}_{2}\right]=2.95 \times 10^{17} \mathrm{~cm}^{-3}(1)$ and $8.88 \times 10^{17} \mathrm{~cm}^{-3}(2)$. The $\mathrm{CS}_{2}+3 \mathrm{O}_{2}$ mixture, $\mathrm{T}_{0}=300 \mathrm{~K}, \mathrm{I}_{\mathrm{H}}=1 \times 10^{5} \mathrm{~N}_{\mathrm{L}}$ photon $/ \mathrm{cm}^{2} \cdot \mathrm{s}$.

Figure 3 presents the dynamics of reflection coefficient arising due to heat release. As is seen, the peak related to heat release directly upon photodissociation, which has a width of the order of time needed for pressure equalization in the system, is followed by another peak induced by heat release in secondary reactions of radicals $\mathrm{CS}$ and atoms $\mathrm{S}$ with $\mathrm{O}_{2}\left(\mathrm{CS}_{2}\right.$ is completely dissociated at the intensity of the incident wave $I_{H}=3 \times 10^{4} \mathrm{~N}_{L}$ photon $/ \mathrm{cm}^{2} \mathrm{~s}$ in times of about $1 \mu \mathrm{s}$ ). The last thermochemical mechanism of nonlinearity should evidently be still more essential at much smaller $I_{H}$, since contrary to the direct heating upon dissociation, proportional to $I_{H}$, heating in secondary reactions due to chemical chain existence is practically independent of $\mathrm{I}_{\mathrm{H}}$. 


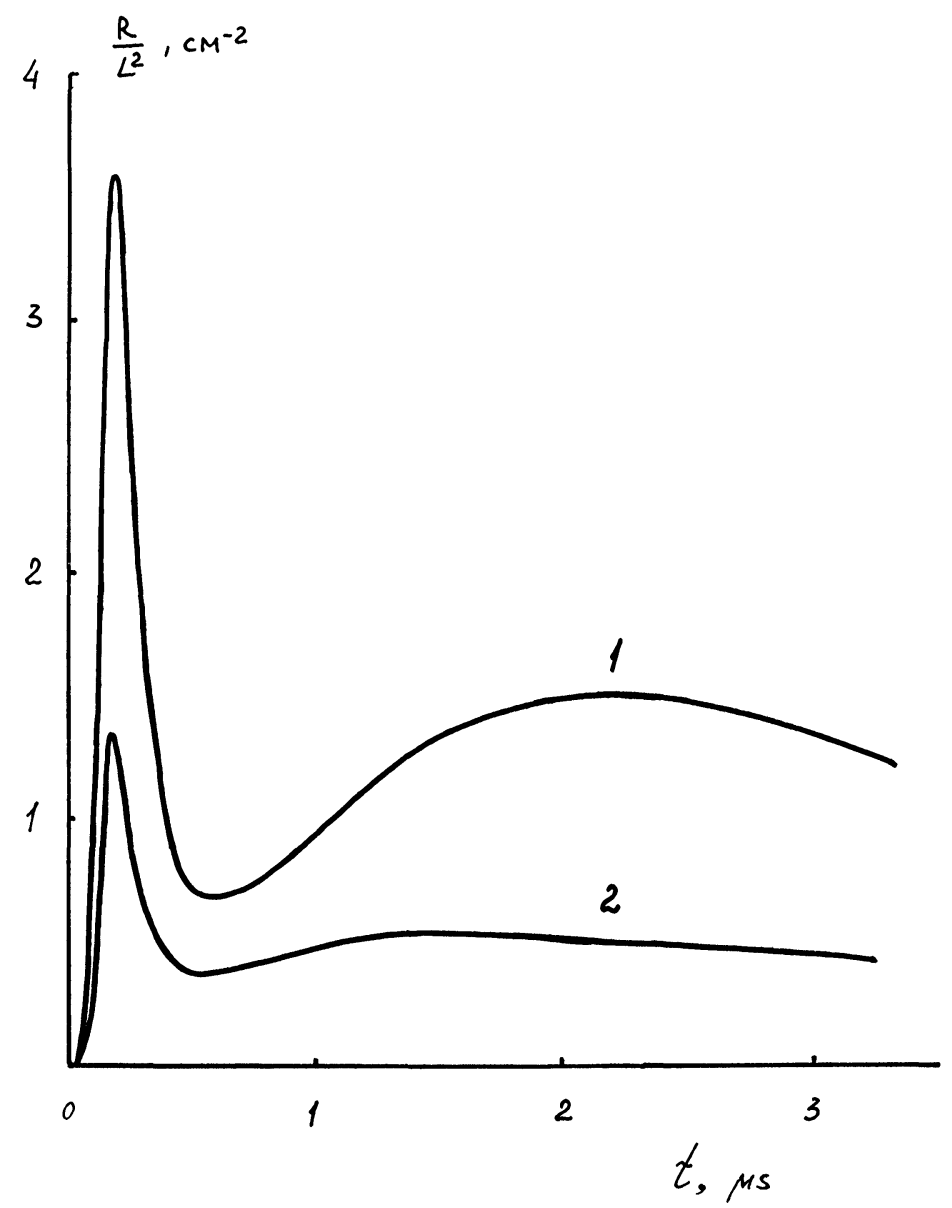

Figure 3 Dynamics of reflection from thermal gratings at large intensities of pump waves. $\mathrm{I}_{\mathrm{H}}=3 \times 10^{4} \mathrm{~N}_{\mathrm{L}}$ photon $/ \mathrm{cm}^{2} \cdot \mathrm{s}(1) ; 5 \times 10^{4} \mathrm{~N}_{\mathrm{L}}(2)$. The $\mathrm{CS}_{2}+3 \mathrm{O}_{2}$ mixture, $\left[\mathrm{CS}_{2}\right]=2.68 \times 10^{17} \mathrm{~cm}^{-3}, \mathrm{~T}_{0}=1500 \mathrm{~K}$.

It means that by using branched chain chemical reactions, one can obtain the contrast phase gratings and accordingly the efficient phase conjugation for extremely low intensities of electromagnetic wave. Such intensities are small enough to be expected from CW-lasers. The results of our numerical simulation drawn at Figure 4 demonstrate this effect rather brightly.

Combination of nonlinear nature of the DFWM effect with the nonlinear kinetics of branched chain reactions may result in unusual dynamics of DFWM. In particular, the oscillations in the temporal behavior of reflection factor, arising due to some transient processes, become possible at small $\mathrm{I}_{\mathrm{H}}$ (Figure 5).

The results of the present work are as follows: (i) By using photodissociation phenomena, the calculated value of DFWM phenomena reflectivity for the ns pulse 


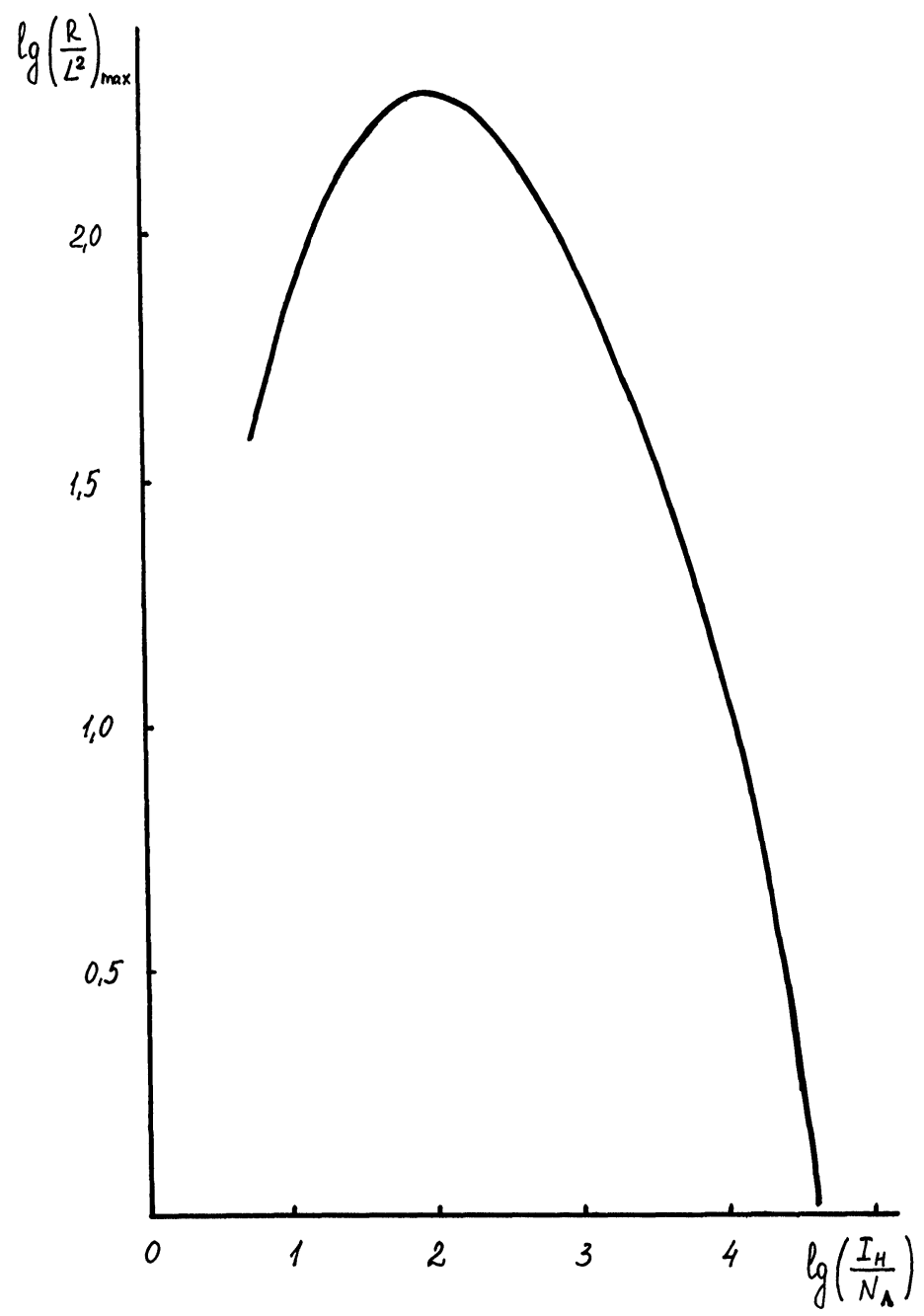

Figure 4 Maximal reflection factor as a function of pump wave intensity for the case of thermal nonlinearity. The $\mathrm{CS}_{2}+3 \mathrm{O}_{2}$ mixture, $\left[\mathrm{CS}_{2}\right]=2.68 \times 10^{17} \mathrm{~cm}^{-3}, \mathrm{~T}_{0}=1500 \mathrm{~K}$.

turns out to be close to those attained for $\mu$ s pulses by the conventional non-chemical methods. By using this phenomenon, the liquid solution of photobleaching dyes, as well as colored gases, may also find their practical applications. In such a case, the maximal value of reflectivity is determined by the reciprocal absorption pathlength. (ii) When laser-induced photodissociation leading to the formation of reactive species gives rise to branched side chain reactions in medium, the addition two-order increase in reflectivity may be expected to occur at rather small intensities of pump wave. 


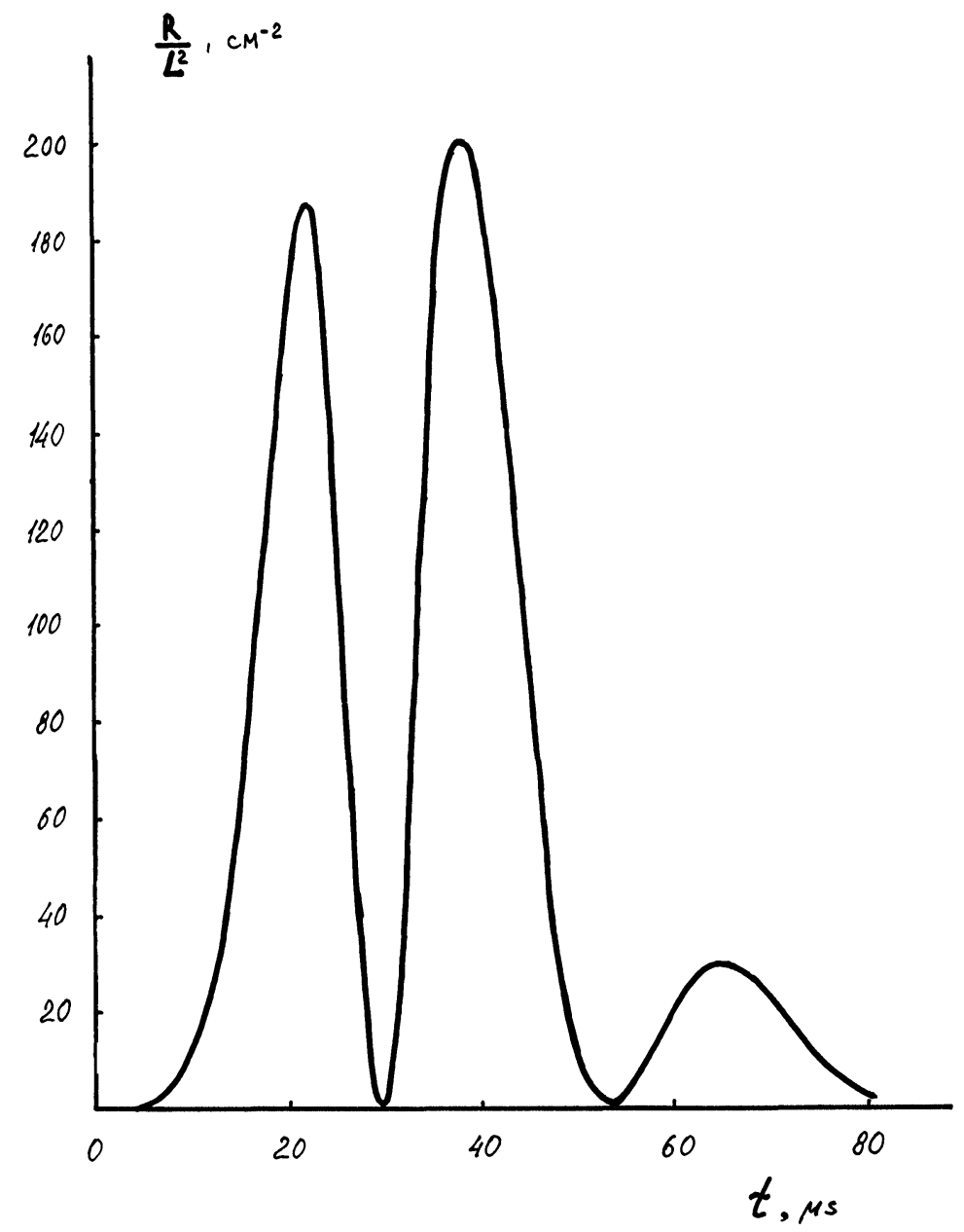

Figure 5 Dynamics of reflection from thermal gratings at low intensity of pumping $\left(\mathrm{I}_{\mathbf{H}}=1.74 \times 10^{20}\right.$ photon $/ \mathrm{cm}^{2} \mathrm{~s}$ ). The $\mathrm{CS}_{2}+3 \mathrm{O}_{2}$ mixture, $\left[\mathrm{CS}_{2}\right]=2.68 \times 10^{17} \mathrm{~cm}^{-3}, \mathrm{~T}_{0}=1500 \mathrm{~K}$.

And accordingly, phase gratings formed due to heat release in chemical reaction may be expected to exist for markedly long time intervals.

We have considered here the case of $\mathrm{CS}_{2} / \mathrm{O}_{2} / \mathrm{Xe}$ gas mixture irradiated with ArF-laser beam $(\lambda 193 \mathrm{~nm})$; the similar results were obtained for the $\mathrm{IBr} / \mathrm{Xe}$ mixture irradiated with the second harmonic of Nd-laser $(\lambda 530 \mathrm{~nm})$ and for $\mathrm{F}_{2} / \mathrm{H}_{2} /$ Xe mixture irradiated with $\lambda \lambda 240-340 \mathrm{~nm}\left(\mathrm{XeF}, \mathrm{KrF}, \mathrm{XeCl}, \mathrm{N}_{2}\right.$ and other UV lasers).

\section{References}

1. N. G. Basov, V. S. Zuev, O. Yu. Nosach and E. L. Orlov. Kvantovaya Elektronika, 7, 2614 (1980) (in Russian). 
2. F. V. Bunkin, N. A. Kirichenko and B. S. Luk'yanchuk. Izv. AN SSSR. Ser. Fis., 45, 1018 (1981) (in Russian ).

3. M. V. Bunkina, N. A. Kirichenko and B. S. Luk'yanchuk. Abstracts XI National Conf. on Coherent and Nonlinear Optics. Yerevan (1982) (in Russian).

4. M. G. Galushkin, E. M. Zemskov, V. N. Klushin, R. N. Onoshko, A. S. Rubanov and K. A. Sviridov. Izv. AN SSSR. Ser. Fiz., 51, 311 (1987) (in Russian).

5. M. S. Kurdoglyan and A. N. Oraevskii. Kvantovaya Electronika, 13, 2051 (1986) (in Russian).

6. M. S. Galushkin, K. A. Sviridov, A. M. Seregin and N. V. Cheburkin. Izv. AN SSSR. Ser. Fiz., 51, 318 (1987) (in Russian).

7. G. A. Askar'yan. Pis'ma ZhTEF, 4, 400 (1966) (in Russian).

8. E. B. Gordon, M. S. Drozdov and Yu. L. Moskvin. Kinetika i Kataliz, 22, 115 (1981) (in Russian).

9. J. W. Rabalais, J. M. McDonald, V. Scherr and S. P. McGlynn. Chem. Rev., 71, 73 (1971). 